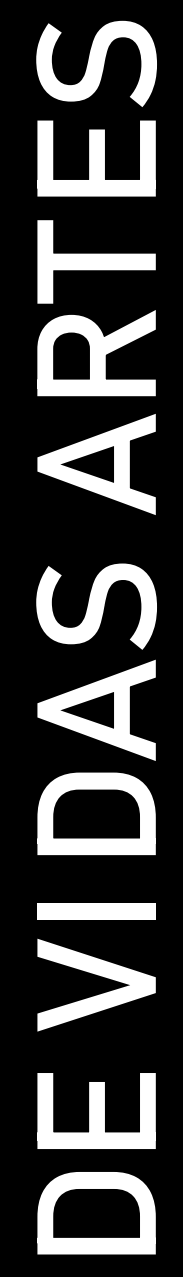

PAULA GUERRA E LÍGIA DABUL (EDS.) 


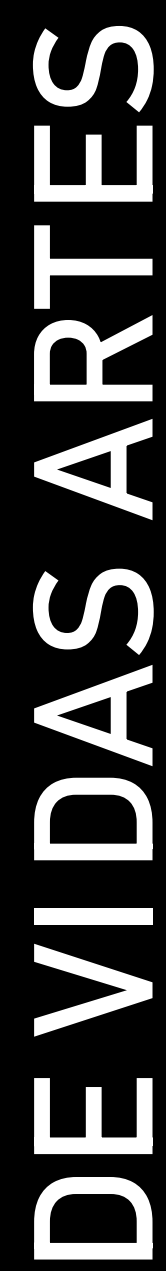

\section{PAULA GUERRA E LÍGIA DABUL (EDS.)}

Design por Irandina Afonso

Ilustração da Capa por Lua Celina

Publicado em Setembro 2019

Universidade do Porto. Faculdade de Letras

[University of Porto. Faculty of Arts and Humanities]

Porto, Portugal

ISBN 978-989-8969-18-7

Suporte: Eletrónico - Formato: PDF / PDF/A 


\title{
II.2. Literatura de cordel no ciberespaço: As tecnologias digitais no processo de escrita
}

\section{II.2. Cordel literature in the ciberespaço: The digital technologies in the written process}

\section{Rafael da Silva da Cunha}

\section{Resumo}

Este capítulo apresenta os resultados de uma pesquisa de mestrado que objetivou compreender como a mediação das tecnologias digitais influenciam o processo de escrita da literatura de cordel, potencializando novas experiências cognitivas. Numa abordagem qualitativa, o método de pesquisa utilizado foi a etnografia virtual, que possibilitou o entendimento da dinâmica da literatura de cordel no ciberespaço, fomentando discussões acerca da escrita mediada por tecnologias digitais. Após a aproximação com o fenômeno estudado, através de diferentes técnicas de obtenção das informações, constatou-se que a literatura de cordel vive um momento de transgressão do suporte textual. Ao alcançar o ciberespaço, os cordelistas passaram a integrar textos, sons e imagens, e a expandir o universo temático do gênero, adotando estratégias de criação específicas para o ambiente virtual.

Palavras-chave: literatura de cordel, tecnologias digitais, modos de escrita.

\begin{abstract}
This chapter presents the results of a master's research that aimed to understand how the mediation of digital technologies influence the writing process of corde/literature, potentializing new cognitive experiences. In a qualitative approach, the research method used was virtual ethnography, which enabled the understanding of the dynamics of cordel literature in cyberspace, fomenting discussions about writing mediated by digital technologies. After the approximation with the studied phenomenon, through different techniques of obtaining information, it was verified that the corde/ literature lives a moment of transgression of the textual support. In reaching the cyberspace, the cordelistas began to integrate texts, sounds and images, and to expand the thematic universe of the genre, adopting specific creation strategies for the virtual environment.
\end{abstract}

Key words : cordel literature, digital technologies, writing modes.

\section{Introdução}

A literatura de cordel é um gênero literário que apresenta regras claras quanto a rima, métrica e estruturação dos textos ${ }^{88}$. Em seus primórdios no Brasil, era impressa em folhetos e vendida nas feiras e estações ferroviárias da região

\footnotetext{
${ }^{88}$ Este capítulo resulta do desenvolvimento da pesquisa de mestrado intitulada "Literatura de cordel em rede: o fazer com tecnologias digitais" em 2018, vinculada ao Programa de Pós-Graduação em Cognição, Tecnologias e Instituições da Universidade Federal Rural do Semiárido sob orientação científica da Professora Doutora Gerciane da Costa Oliveira.
} 
Nordeste. Com o advento das Tecnologias da Informação e Comunicação (TIC), novos espaços de circulação do texto poético foram oportunizados, possibilitando-o transcender os limites geográficos. Sem abandonar sua forma tradicional de circulação, a literatura de cordel encontrou nas mídias de massa, tais como o rádio e a televisão, um novo espaço de circulação. A partir de entrevistas realizadas com cordelistas, Curran (2014) identificou que, embora inicialmente o advento dessas mídias tenham enfraquecido a produção e circulação da literatura de cordel, posteriormente os resultados foram positivos, já que começaram a surgir programas totalmente dedicados ao gênero, ao mesmo tempo em que reportagens jornalísticas vieram a enaltecer sua representatividade cultural nordestina, viabilizando-o alcançar um novo público, localizado em diferentes estados do país.

Do mesmo modo, com o surgimento e popularização da Internet, considerada por Castells (1999) como o meio de comunicação mais revolucionário da chamada "era da informação", surgem outras possibilidades de produção e disseminação de conteúdo, assim como de interação entre pessoas do mundo inteiro através de espaços virtuais ou ciberespaços (Lévy, 1999), favorecendo a manutenção de práticas sociais, tais como a escrita poética. Não se tem relatos sobre qual a primeira experiência de escrita/divulgação de um cordel na rede, porém, identificamos em Amorim (2007) que possivelmente em setembro de 1997 teria ocorrido a primeira peleja ${ }^{89}$ mediada por correio eletrônico, tipo de correspondência oportunizado pela Internet que, na época, ainda era uma novidade, assim como o computador pessoal. A consagrada Peleja virtual entre Américo Gomes (PB) e José Honório (PE): a primeira cantoria via Internet foi impressa posteriormente em folhetos e constitui-se como o grande marco cibernético. A utilização da Internet tem possibilitado que cordelistas famosos e "anônimos" disseminem suas obras em sites, blogs e redes sociais, utilizandose de diferentes recursos na composição da escrita. Ao mesmo tempo em que oportunizam a escrita individual, os recursos do ciberespaço também potencializam processos de escritas colaborativas, que podem ocorrer de forma síncrona e assíncrona. Nesse sentido, Lévy (2007) argumenta que o

\footnotetext{
${ }^{89}$ Disputa poética tradicional no Nordeste brasileiro, na qual dois cantadores enfrentam-se compondo versos improvisados sobre assuntos diversos, com o objetivo de vencer seu oponente (Abreu, 1999). Quando ganham forma impressa, as pelejas passam a ser consideradas uma variedade temática da literatura de cordel (Batista, 1977).
} 
ciberespaço reúne uma infinidade de mídias e interfaces que possibilitam o desenvolvimento da inteligência coletiva, mediante a interação dos indivíduos.

Dessa forma, sendo a literatura de cordel brasileira um gênero literário que, em seu percurso histórico, mostra-se flexível e adaptável aos novos meios de comunicação que surgem junto ao processo de desenvolvimento da sociedade, consideramos necessário compreender como ela se mantém em meio a grande quantidade de informação e gêneros literários que se encontram disponíveis no ciberespaço. Enquanto transita entre a forma impressa, o rádio e a televisão, a literatura de cordel parece fazer um movimento de alternância entre a escrita e a oralidade, utilizando-as como estratégias para manutenção e disseminação do gênero. Com o surgimento e popularização do computador e da Internet, novas possibilidades e desafios apresentam-se aos cordelistas. Por um lado, há uma diversidade de recursos que podem ser utilizados, tanto para a composição quanto para a divulgação do texto poético, tais como, imagens, sons, hiperlinks, entre outros. Em contrapartida, a rapidez com que as informações circulam na rede exige novas estratégias que aproximem o público leitor.

No que se refere à utilização de artefatos técnicos na escrita da literatura de cordel, entendemos que as tecnologias digitais podem provocar deslocamentos e transformações nos modos de escrever e na própria escrita poética. Assim, o objetivo geral dessa pesquisa foi compreender como a mediação das tecnologias digitais influenciam no processo de escrita da literatura de cordel, potencializando novas experiências cognitivas.

A principal contribuição deste trabalho está na possibilidade de identificarmos como a literatura de cordel se faz presente no ciberespaço, e como os cordelistas compreendem as implicações das tecnologias digitais e dos novos espaços de circulação do cordel em suas práticas de escrita. Do ponto de vista teórico-prático, possibilitou discussões relevantes acerca da função exercida pela literatura de cordel em um contexto de invenção da região Nordeste, assim como das alterações nos modos de escrita a partir da integração de novos artefatos técnicos, sobretudo das tecnologias digitais.

\section{Notas sobre a literatura na era da cibercultura}

Conforme afirma Castells (1999), vivemos atualmente a era da informação, na qual as pessoas encontram-se em conexão com o mundo inteiro através da Internet. A sociedade contemporânea utiliza-se agora de espaços físicos 
e virtuais para a manutenção de suas práticas sociais. Este espaço virtual, onde os acontecimentos estão constantemente em mutação e as informações circulam em alta velocidade, permitindo a comunicação entre agentes e o desenvolvimento da inteligência coletiva, é denominado por Lévy (1999) como ciberespaço.

Para o referido autor, a Internet é "um tapete de sentido tecido por milhões de pessoas e devolvido sempre ao tear. Da permanente costura pelas pontas de milhões de universos subjetivos emerge uma memória dinâmica, comum, objetivada, navegável" (Lévy, 1999: 114). Essa dinâmica interativa, advinda da união das telecomunicações com a informática, que promove interações sociais, culturais e tecnológicas em rede, pode ser compreendida como cibercultura. Se as pessoas agora habitam uma nova dimensão, a dimensão virtual, a literatura, que é uma prática social, também seguiu essa tendência e adentrou ao ciberespaço. Para Machado (2002) trata-se de um processo natural, considerando-se que a arte se faz com os recursos de seu tempo, e como estamos vivendo a era das TIC, as artes midiáticas podem ser consideradas a expressão da criação artística atual, as quais manifestam toda a sensibilidade e o conhecimento do homem do século XXI.

A transição do texto impresso para o meio digital foi impulsionada pelo surgimento dos e-books, livros em formato digital, e desde que a literatura passou a circular no ciberespaço, a digitalização dos textos tornou-se um assunto amplamente discutido em jornais, livros, artigos acadêmicos e demais veículos de comunicação. Entretanto, conforme expõe Duarte e Alcântara (2011), essas primeiras publicações tratam apenas da digitalização de obras já existentes e consagradas e/ou de novas obras publicadas nas versões impressa e digital, isto é, não trazem uma abordagem sobre um novo modo de se fazer literatura, utilizando-se dos recursos que a tecnologia oferece.

O panorama atual da presença dos gêneros literários no ciberespaço exige que os novos estudos sobre essa temática, abordem de forma mais abrangente as alterações e reinterpretações que estes sofreram no ciberespaço. Isso é necessário ao consideramos que, agora, além da transição do papel para o digital, existem obras que são feitas exclusivamente para o universo virtual, as quais utilizam-se dos diferentes recursos midiáticos nele disponíveis, com vistas a atrair um novo público, sedento por tecnologia, informação e inovação. Assim, buscamos nesse trabalho apresentar o 
panorama atual da literatura de cordel no ciberespaço, analisando as transformações decorrentes da integração das TIC no processo criativo dos cordelistas, e delineando as especificidades que o gênero assume ao ser produzido na Internet, e para a Internet. Para isso, é importante refletirmos sobre a utilização destas novas ferramentas no processo de composição da escrita, o que faremos na seção seguinte.

\section{As tecnologias digitais no processo de composição da escrita}

Abordar os processos que configuram o escrever com tecnologias digitais implica, necessariamente, em repensar as formas de interação do homem com esses dispositivos técnicos e, principalmente, definir como tais dispositivos são compreendidos nesse processo. Nesta pesquisa, propomos conceber as tecnologias digitais não como simples instrumentos que possibilitam a ampliação de competências já adquiridas, neste caso, a prática da escrita, mas como constituintes destas próprias competências. Lévy (1993) enfatiza que novas maneiras de pensar e de conviver estão sendo elaboradas no mundo das telecomunicações e da informática. Na época atual, os diferentes dispositivos informacionais interferem diretamente nas relações entre o homem, o trabalho e a própria inteligência, e se constituem como um dos principais agentes de transformação das sociedades. Dessa forma, acredita que "não há nenhuma distinção real bem definida entre o homem e a técnica, nem entre a vida e a ciência, ou entre o símbolo e a operação eficaz ou a poiésis e o arrazoado" (Lévy, 1993: 14).

Por entender que as tecnologias são decorrentes do processo de evolução humana e contribuem para formar e estruturar o funcionamento das sociedades e as aptidões das pessoas, uma vez que são importantes fontes de imaginário, entidades que participam plenamente da instituição de mundos percebidos, Lévy (1993) propõe o fim da pretensa oposição entre o homem e a máquina e defende que não podemos reduzi-la a seu uso instrumental.

O surgimento de novas tecnologias de representação e de manipulação da informação marcam etapas importantes na aventura intelectual humana. Foi assim com a oralidade, a escrita e, mais recentemente, com a informática, as quais Lévy (1993) denomina de "tecnologias intelectuais". Vale salientarmos que em nenhum momento o autor pressupõe o domínio de uma tecnologia sobre a outra. Ao contrário, indica que a utilização de uma determinada tecnologia "[...] coloca uma ênfase 
particular em certos valores, certas dimensões da atividade cognitiva ou da imagem social do tempo, que tornam-se então mais explicitamente tematizadas e ao redor das quais se cristalizam formas culturais particulares" (Lévy, 1993: 128).

Podemos inferir que as tecnologias intelectuais condicionam novos processos cognitivos e discursivos, na medida em que reorganizam e ampliam a visão de mundo de seus usuários, alteram seus reflexos mentais, suas formas de comunicação e organização, sua ecologia cognitiva ${ }^{90}$. Existe, portanto, uma relação de reciprocidade entre o homem e os objetos técnicos. Para Lévy (1993), a inteligência ou a cognição são o resultado de redes complexas onde interagem um grande número de atores humanos, biológicos e técnicos. Assim, o homem não é inteligente por si só, mas por sua interação com o grupo no qual está inserido, com a língua, e com toda uma herança de métodos e tecnologias intelectuais, dentre as quais o uso da escrita e da informática.

O sujeito cognitivo só funciona através de uma infinidade de objetos simulados, associados, imbricados, reinterpretados, suportes de memória e pontos de apoio de combinações diversas. Mas estas coisas do mundo, sem as quais o sujeito não pensaria, são em si produto de sujeitos, de coletividades intersubjetivas que as saturaram de humanidade. E estas comunidades e sujeitos humanos, por sua vez, carregam a marca dos elementos objetivos que misturam-se inextrincavelmente à sua vida, e assim por diante, ao longo de um processo em abismo no qual a subjetividade é envolvida pelos objetos e a objetividade pelos sujeitos (Lévy, 1993: 174).

Nessa perspectiva, observamos que o pensamento é um devir coletivo no qual homens e artefatos tecnológicos se misturam. Estes artefatos desempenham um papel fundamental nos coletivos pensantes, não sendo possível utilizá-los sem interpretá-los. "Nenhuma técnica tem uma significação intrínseca, um 'ser' estável, mas apenas o sentido que é dado a ela sucessiva e simultaneamente por múltiplas coalizões sociais" (Lévy, 1993: 188). Lévy (1993) nos auxilia na compreensão de que as tecnologias só podem ser determinadas pelo uso que fazemos delas e pela interpretação que Ihes atribuímos. Por outro lado, quando delas nos apropriamos, nos modificamos cognitivamente e um novo estilo de humanidade é inventado. As tecnologias estão em nós, através da imaginação e da aprendizagem. Mesmo quando não estamos utilizando qualquer dispositivo, nossas ações são por

\footnotetext{
90 Lévy (1993) define a ecologia cognitiva como o estudo das dimensões técnicas e coletivas da cognição. Para o autor, a inteligência é sinônimo de cognição.
} 
eles determinadas. Pensamos com escritas, métodos, operações lógicas, modos de representação e de visualização diversas.

Um outro teórico que nos proporciona uma visão mais abrangente acerca da interação do homem com os objetos técnicos e, consequentemente, nos ajuda a refletir sobre a escrita com tecnologias digitais, é o filósofo francês Gilbert Simondon (1989). Segundo o autor, há uma certa resistência por parte do homem em atribuir às tecnologias sua devida importância, reduzindo-as a uma dimensão utilitarista, de uso e domínio. Esse entendimento não leva em consideração que as tecnologias resultam de projetos humanos, e que, em diferentes épocas, elas foram essenciais para a nossa própria existência. Isto posto, é preciso desconstruir a ideia de que a técnica se opõe ao sujeito.

A oposição sustentada entre a cultura e a técnica, entre o homem e máquina, é falsa e sem fundamento; ela esconde ignorância e ressentimento. Por trás de um humanismo fácil, ela mascara uma realidade rica em esforços humanos e em forças naturais, e que constitui o mundo dos objetos técnicos, mediadores entre a natureza e o homem (Simondon, 1989: 09).

Simondon (1989) propõe que os objetos técnicos sejam compreendidos como extensões humanas, considerando-se que, quando acoplados aos sujeitos, estes dispositivos promovem uma organização dos sistemas psíquicos, afetivos e, consequentemente, sociais. Em uma sociedade onde os objetos técnicos se fazem cada vez mais presentes, nos mais variados setores, não é aceitável que nós, enquanto produtores e produtos dessas tecnologias, tenhamos uma visão reducionista sobre elas, que estejamos sempre com o propósito de as controlar. Desse modo, precisamos nos tornar organizadores dessa sociedade de objetos técnicos, que concebem as tecnologias como um acoplamento humano e produzem conhecimentos, reconfigurando o próprio viver. Corroborando com os autores supracitados, Guattari (1992) entende que o acoplamento dos homens com as tecnologias dispara novos processos cognitivos, transformando-os a cada interação. Neste complexo processo,

As máquinas tecnológicas de informação e de comunicação operam no núcleo da subjetividade humana, não apenas no seio de suas memórias, da sua inteligência, mas também de sua sensibilidade, dos seus afetos, dos seus fantasmas inconscientes (Guattari, 1992: 14).

Assim, a partir das contribuições teóricas dos supracitados autores, adotamos nesse estudo a percepção de que o acoplamento dos seres humanos com os objetos técnicos determina um processo interno criativo que 
pode ser visto como o próprio processo do conhecer. Ao interagir com as tecnologias digitais, o indivíduo transforma-se profundamente, desenvolvendo novas e diferentes capacidades e habilidades. Toda essa discussão mostra-se relevante no nosso estudo, pois, concordamos que as alterações nos modos de escrita a partir da integração das tecnologias digitais nesse processo implicam em mudanças cognitivas, subjetivas, e no próprio material que está sendo construído, neste caso, textos em literatura de cordel. Queremos esclarecer que as técnicas e instrumentos utilizados para concretização de uma ideia, construção e exposição de uma obra, não podem ser tidas apenas como ferramentas de mediação indiferentes aos resultados obtidos, que poderiam ser substituídas por quaisquer outras, sem provocar alterações no que está sendo produzido. Ao contrário, estes recursos tecnológicos propiciam condições de criação bastante especificas, tendo em vista que estão carregados de conceitos que influenciam diretamente no resultado (Machado, 2002).

Conforme Domingues (1997), o espaço de criação, assim como os instrumentos utilizados no processo criativo, provoca a "inspiração" e as intenções poéticas dos artistas, na medida em que estes se conectam ao ambiente e as informações nele contidas, e se revitalizam permanentemente com saberes científicos. Sendo assim, as adversidades que podem surgir durante o desenvolvimento de uma obra, sejam de ordem técnica (problemas com hardwares ou softwares) ou cognitiva (desvios de pensamento, aspecto emocional, etc.), são determinantes no resultado do trabalho. Em concordância com Demoly (2008), compreendemos que as tecnologias digitais têm expandido a forma como escrevemos, sobretudo, quando essa escrita acontece no ciberespaço, onde textos, imagens, sons e hiperlinks, mesclam-se em uma convergência de mídias que favorecem novos modos de fazer.

Um dos pontos a salientar é que a convergência de mídias significa novas e inusitadas coordenações de ações, pois passamos a operar com imagens e sons, formas de linguagem que transformam o escrever e que parecem engajar mais e mais as pessoas na escritura (Demoly, 2008: 62).

Encontramos no ciberespaço a possiblidade de fazer com o outro, em regime de colaboração. $O$ acesso à Internet eliminou as barreiras espaciais e temporais que impediam a comunicação entre pessoas geograficamente distantes, viabilizando a interconexão, a criação de comunidades virtuais e a inteligência coletiva, conforme evidencia Lévy (1999). Demoly (2008) enfatiza 
que o computador e a Internet conceberam uma nova dinâmica de escrita, ao passo que temos acesso a uma infinidade de conteúdo que podem vir a subsidiar nossa produção. Com as ferramentas de copiar e colar podemos retirar fragmentos de textos, dispondo-os do modo como queremos em um verdadeiro movimento de tessitura em rede. Além disso, no computador os limites entre o pensar e o escrever tornam-se menos nítidos, pois ao escrever um texto é possível acrescentar, interromper ou eliminar frases num ritmo muito próximo ao ritmo do ato de pensar (Dias, 2000). Assim, o processo de composição da escrita produz "uma mudança estrutural que pode referir-se, tanto às experiências singulares das pessoas como às mudanças nos modos de cognição e de configuração de redes sociais e tecnológicas" (Demoly, 2008: 89). Nessa perspectiva, neste trabalho refletimos sobre como esse acoplamento com as tecnologias digitais no processo de escrita da literatura de cordel desencadeia novas experiências cognitivas e promove alterações na obra produzida, especialmente quando acontece colaborativamente em redes de escrita.

\section{Metodologia}

A pesquisa que desenvolvemos apresenta abordagem qualitativa e natureza exploratória. Para Gil (2010), pesquisas exploratórias têm como principal finalidade, estabelecer uma maior aproximação com o fenômeno investigado, de modo a torná-lo mais explícito e/ou constituir hipóteses pesquisáveis em estudos posteriores. Em geral, pesquisas dessa natureza envolvem levantamentos bibliográficos, entrevistas com atores que experienciam o problema pesquisado, e análise de elementos que possibilitem a compreensão do objeto. Como método de pesquisa, optamos pela utilização da etnografia, tendo em vista as características de nosso campo de estudo. A etnografia é um método de investigação característico da antropologia, recorrentemente utilizado em pesquisas das ciências sociais, que propõe uma maior aproximação do pesquisador com o contexto que será investigado. De acordo com Mattos (2011), trata-se de uma abordagem de pesquisa científica na qual a observação direta é parte integrante, e toda investigação é conduzida pelo senso questionador do etnógrafo; portanto, a utilização de técnicas e procedimentos não segue, necessariamente, padrões rígidos e/ou pré-determinados, podendo ser formulados ou reelaborados a partir das questões propostas pelo pesquisador. 
Mediante as características que envolvem nosso estudo, utilizamos como método de pesquisa a etnografia virtual. A pesquisadora Christine Hine foi a responsável pela popularização do termo etnografia virtual (Fragoso et al., 2011), que surge apoiado na necessidade de discutir a questão no âmbito epistemológico, questionando-se sobre a adaptação da etnografia ao contexto cibernético, no qual a cultura também se constitui. Hine (2004) enfatiza que a etnografia virtual deve ser compreendida por sua natureza qualitativa, situando o estudo da Internet a partir de duas perspectivas: como cultura e como artefato cultural. Além disso, a autora considera que sua aplicação se dá no, e através do, espaço on-line, não podendo ser desvinculada do off-line. A pesquisa foi realizada utilizando os seguintes procedimentos metodológicos: pesquisa de sites, blogs e páginas em redes sociais que têm como temática central a literatura de cordel; seleção e envio de convites aos cordelistas para participarem da pesquisa; assinatura do Termo de Consentimento Livre e Esclarecido (TCLE) e realização das entrevistas; observação etnográfica da dinâmica de produção dos cordelistas em suas páginas; análises e discussões dos dados.

No primeiro momento buscamos identificar, através de ferramentas on-line de pesquisa, blogs e sites em que circula a literatura de cordel. $\mathrm{O}$ mesmo procedimento foi realizado em três redes sociais (Facebook, Instagram e YouTube), objetivando identificar páginas e canais que disseminem o gênero. Utilizamos como palavras-chave para as buscas os termos "literatura de cordel", "cordel", "cordelista", "repente" e "nordeste", que nos apresentaram centenas de resultados.

Após a identificação desses ambientes, verificamos e selecionamos a amostra que compôs o corpus da nossa pesquisa. Inicialmente, utilizamos para seleção o seguinte critério de inclusão: estar em atividade, tendo ao menos duas publicações de literatura de cordel até janeiro do presente ano, 2019. No entanto, ainda tivemos como retorno uma grande quantidade de páginas Web, sendo necessário estabelecermos outros critérios, a saber: páginas cujo conteúdo disseminado seja, em sua maior parte, literatura de cordel; e páginas de maior alcance de público (acessos, curtidas e compartilhamentos). Nesta fase, selecionamos dez páginas Web, entre blogs, canais do YouTube, páginas do Facebook e perfis no Instagram. No segundo momento, entramos em contato com os cordelistas/administradores desses espaços virtuais, através do e-mail por eles disponibilizados, assim como 
pelas ferramentas de mensagens disponíveis em suas páginas. Após o envio dos convites, obtivemos retorno de seis cordelistas, para os quais enviamos o TCLE. Ter o documento devidamente assinado foi condição necessária para participação na próxima fase da pesquisa, a das entrevistas. Optamos também por só utilizar para análise as páginas dos cordelistas que nos enviassem o termo. Quatro cordelistas nos retornaram o documento e participaram das entrevistas. Consequentemente, suas páginas tornaram-se nosso material de estudo, a saber: Cordelando ${ }^{91}$ (b/og); Cordel animado ${ }^{92}$ (canal do YouTube); Um repente por dia ${ }^{93}$ (perfil no Instagram); Um cordel $^{94}$ (blog).

\section{Processos que configuram o escrever literatura de cordel com tecnologias digitais}

A partir das discussões teóricas tecidas anteriormente, das observações etnográficas e das entrevistas realizadas com os cordelistas que atuam no ciberespaço, propomos aqui repensar os processos que configuram o escrever literatura de cordel a partir do acoplamento com as tecnologias digitais. A escrita é uma criação que se apropria das tecnologias e implica em experiências cognitivas que transformam o próprio sujeito e o que ele produz. Logo, não podemos compreender a literatura de cordel que permeia 0 ciberespaço, da mesma forma que compreendemos aquela produzida especificamente para ser impressa em folhetos.

Encontramos nas páginas analisadas uma grande variedade de produções em literatura de cordel. Nos dedicamos a conhecer cada uma delas para compreendermos as especificidades que o gênero apresenta no ciberespaço. Assim, observamos as temáticas recorrentes, o plano composicional, o estilo e a utilização das mídias (textos, imagens, sons) na composição das obras, pensando-as como resultantes do processo de apropriação das tecnologias. A literatura de cordel, desde os primórdios, mostrou-se propensa a tratar sobre múltiplos temas. Em uma época onde o folheto era o principal meio de informação e entretenimento, os romances, contos fantásticos, fenômenos da natureza (secas e enchentes), e acontecimentos jornalísticos, tornaram-se temáticas recorrentes. $\mathrm{Na}$

\footnotetext{
${ }^{91}$ Disponível em: http://cordelando389.blogspot.com/. Acesso em: 20 jul. 2018.

92 Disponível em: https://www.youtube.com/channel/UCGr9TFCIdQLdRPtoL7bqt8g/feed. Acesso em: 20 jul. 2018.

${ }^{93}$ Disponível em: https://www.facebook.com/UmRepentePorDia/>. Acesso em: 20 jul. 2018.

${ }^{94}$ Disponível em: https://www.umcordel.com/. Acesso em: 20 jul. 2018.
} 
atualidade, estas temáticas ainda aparecem, mas, com menor frequência. Há uma predileção por parte dos cordelistas por temas contemporâneos (Resende, 2005).

Isso acontece, sobretudo, no ambiente online, onde a informação circula em tempo real e os acontecimentos estão constantemente em transformação. Com a Internet, ampliaram-se as possibilidades de socialização e produção de conteúdo. Tudo está em constante processo de atualização. Ambientes como as redes sociais, promovem a interação entre as pessoas, que cada vez mais compartilham suas vivências. Conversa-se sobre tudo, o tempo todo. Toda essa dinâmica de produção e circulação da informação é levada em consideração no processo criativo da literatura de cordel para a Internet. Percebemos que há uma preocupação por parte dos cordelistas em produzirem obras que promovam a identificação do público, por isso, os temas explorados estão cada vez mais abrangentes e atuais. Os excertos a seguir, extraídos das entrevistas com cordelistas, confirmam nossa percepção:

\footnotetext{
Eu acredito que com o uso da Internet os assuntos motivadores para se escrever um texto aumentaram muito, principalmente pelo fato de estarmos conectados com tudo que acontece. Observo o cotidiano, assuntos que causam discussão nas redes sociais; principalmente a nossa política. Quando vejo algo que merece um texto, simplesmente escrevo. (Cordelista - Um cordel).

Ao escrever para a Internet, procuro trazer temas mais abrangentes e de forma mais objetiva. (Cordelista - Cordelando).

Começo com uma ideia principal, uma temática que chame atenção, que seja contemporânea em algum aspecto. Quando trato de temas como sertão, tento fazer alguma ligação com temas atuais, nem que essa ligação seja apenas uma palavra, um meme ou algo do tipo. (Cordelista - Um repente por dia).
}

Ao observarmos as produções dos cordelistas em suas páginas Web, constatamos que não existem restrições temáticas. Qualquer assunto/acontecimento pode se tornar fonte de inspiração para a construção de um cordel. Os temas abordados vão desde acontecimentos da vida cotidiana, até problemas sociais. A questão da corrupção é uma das mais comentadas pelos cordelistas. Juntam-se a ela, o problema da violência e do preconceito em suas diversas formas, as datas comemorativas e as vivências com as novas tecnologias. As músicas mais tocadas no país e no mundo também servem de inspiração para os cordéis, ao mesmo tempo em que ainda há forte repetição de estereótipos do homem sertanejo. A escrita de 
contos e romances em literatura de cordel também se faz presente nos ambientes virtuais. No canal Cordel animado, por exemplo, encontramos diversas histórias rimadas que misturam ficção e realidade, direcionadas ao público infantil. Temos ainda, uma grande quantidade de cordéis informativos, elaborados com o objetivo de disseminar assuntos de interesse social.

No blog Cordelando temos uma outra questão para refletirmos. $\mathrm{Na}$ apresentação do cordel As viroses do aedes, o(a) cordelista deixa claro que a motivação para escrevê-lo foi a calorosa recepção por parte dos leitores, de um cordel escrito anteriormente com a mesma temática. Assim, enfatizamos que o público tem forte influência no processo de definição do tema e criação do cordel, como destacam os(as) próprios cordelistas:

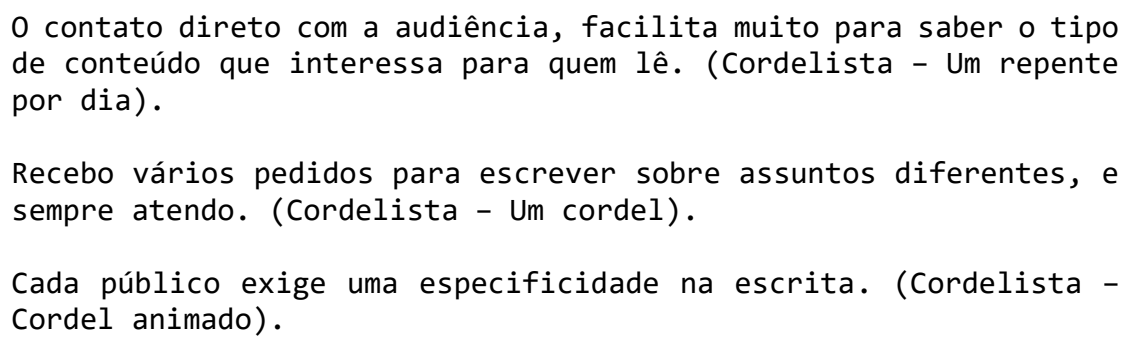

Essa valorização da opinião do público fica ainda mais evidente em um Instagram stories ${ }^{95}$ publicado no perfil da Um repente por dia no Instagram. Na oportunidade, o(a) cordelista/administrador(a) pede sugestões de temas aos seus seguidores para o próximo cordel que será publicado. Escrever para a Internet implica necessariamente repensar todo o processo de composição da obra. Definir o tema que será tratado na literatura de cordel, que inspira a composição de uma obra, faz parte do processo inicial de escrita. O cordelista do meio virtual tem levado em consideração, além do seu próprio interesse pela temática, os assuntos que estão em ênfase no momento e o público para o qual sua produção será destinada. Considerar esses aspectos já suscita em mudanças no fazer, mas não é só isso. O acoplamento com as tecnologias dispara mobilizações internas que transformam a subjetividade, as formas de inspiração.

\begin{abstract}
Mudam as tecnologias, mas não mudam elas sem transformarem os ritmos, os apelos ao escrever, as formas da inspiração. A folha em branco enquadra $o$ escrever nas coordenadas geográficas da altura e da largura; situa-o no mundo físico da estabilidade. Mas a tela do computador é móvel. Seu dinamismo vem de dentro e empurra a escrita para a frente ao mesmo passo que busca escondêla em seu interior (Marques, 2006: 32).
\end{abstract}

95 O Instagram Stories é um recurso disponível no Instagram que dá aos usuários a possibilidade de criarem fotos e vídeos curtos, que desaparecem depois de 24 horas da sua publicação. 
Durante o processo de criação para a Internet, os cordelistas se apropriam de diferentes dispositivos técnicos. $\mathrm{Na}$ fase inicial, alguns ainda mantém o hábito de esboçarem seus versos de forma manuscrita, mas a finalização e composição da obra é oportunizada pelas tecnologias digitais. Vejamos os excertos a seguir:

\footnotetext{
Começo a esboçar os versos manuscritos e a escrita final é feita no computador (Cordelista - Cordel animado).

Uso as ferramentas tradicionais, computador, celular, blog, e redes sociais. Sempre que escrevo um poema de cordel eu gosto de utilizar uma imagem para chamar a atenção. (Cordelista - Um cordel).

A maior parte do trabalho é todo feito no computador, às vezes utilizo o smartphone, quando a ideia surge enquanto não estou em casa. Quando escrevo à mão alguma coisa, são apenas fragmentos para serem desenvolvidos depois. Sempre tenho um computador disponível com algum software de edição de texto. Trabalho principalmente com imagens. Geralmente é uma arte que simula um papel de cordel, com o texto no centro. (Cordelista - Um repente por dia).

Escrevo em momento de privacidade, em minha residência; lugar tranquilo, caneta, papel e imaginação solta. Utilizo programas de edição de imagem e vídeo para fazer a divulgação de meus trabalhos através das redes sociais. (Cordelista - Cordelando).
}

As ferramentas disponíveis nos computadores e na Internet, possibilitam a emergência de obras que integram textos, imagens e sons, atualizando os modos de fazer e apresentar a literatura de cordel.

Pela primeira vez, no mesmo suporte, o texto, a imagem e o som podem ser conservados e transmitidos. Imediatamente, toda a realidade do mundo sensível pode ser apreendida através de diferentes figuras, de sua descrição, de sua representação ou de sua presença. (Chartier, 1998: 134).

Nas páginas que analisamos, encontramos o que Demoly (2008) chama de uma convergência de mídias. No canal de vídeos Cordel animado, por exemplo, o(a) cordelista combina seus contos em literatura de cordel com música e sonoplastia. Nos vídeos, o cordel recitado ganha vida através de dramatizações com fantoches, e o cenário montado em sua casa dispõe de elementos que remetem ao conteúdo da história e ajudam na composição de um produto audiovisual de ótima qualidade.

A integração da literatura de cordel com o audiovisual também é feita pelo(a) cordelista do blog Cordelando. Os vídeos são confeccionados a partir de histórias reais contadas de forma rimada, com músicas e imagens que, em grande parte, são fotos das pessoas homenageadas no cordel. Também é comum encontrar no Cordelando a apresentação do texto escrito com 
imagens associadas. Essa é uma das formas mais comuns de composição da literatura de cordel no ciberespaço, e também aparece no blog Um cordel. Na página Um repente por dia, o(a) cordelista costuma utilizar na composição de seus cordéis sempre a mesma imagem como plano de fundo. Trata-se de uma arte pensada para lembrar o papel no qual os primeiros cordéis eram impressos. O texto é disposto no centro da imagem, e a logomarca da página, no canto inferior. Outra forma de associação entre texto e imagem explorada pela Um repente por dia, se dá com xilogravuras digitais, uma colaboração com a página Estilo xilo ${ }^{96}$.

Ainda tratando sobre as mídias utilizadas na composição da obra, direcionamos agora as nossas análises para a mídia textual, mais especificamente para o plano composicional (estrutura formal) da literatura de cordel no ciberespaço. Desde o início da produção de folhetos no Brasil, atender as métricas e explorar os recursos poéticos do ritmo e das rimas são condições necessárias para uma poesia ser classificada como literatura de cordel. No ciberespaço, não poderia ser diferente. Verificamos nas páginas observadas o uso de diferentes métricas da literatura de cordel. A setilha é a métrica mais utilizada nos cordéis da página Um repente por dia, já as estrofes de quatro versos aparecem mais esporadicamente. Nos blogs Cordelando e Um cordel, o uso da sextilha predomina nas produções, porém, também são encontrados cordéis escritos em décimas.

É importante ressaltarmos que o fato da literatura de cordel está sendo produzida dentro dos códigos formais e ideológicos do gênero não contradiz nossa percepção acerca do fazer com tecnologias digitais. Os teóricos com os quais dialogamos nos ajudam a pensar a interação humana com as tecnologias como processos disparadores de mudanças cognitivas, que potencializam novas coordenações de ações. Alteram-se as tecnologias, alteram-se os modos de escrever e, consequentemente, altera-se o que está sendo produzido. Nesse sentido, buscamos saber dos próprios cordelistas se eles visualizam essas alterações no processo de escrita após a emergência das tecnologias digitais e do ciberespaço. Vejamos o que dizem:

o ambiente digital é sempre favorável por facilitar uma busca, acessar dicionários e, principalmente, na hora de publicar. Tudo isso, juntamente com o feedback do público, influencia diretamente na criação. Quando eu ainda tinha pouco contato com a literatura de cordel, a qualidade também era baixa. Após ter um contato maior com o meio digital, conheci vários estilos e passei a errar menos.

\footnotetext{
${ }^{96}$ Disponível em: <https://www.facebook.com/estiloxilo/>. Acesso em: 21 jul. 2018.
} 
Principalmente no que diz respeito às métricas, que é o problema da maioria das pessoas que começam a escrever cordel. A Internet me trouxe as informações que precisei para errar menos. (Cordelista - Um repente por dia).

Sim, principalmente na forma de escrever para um público que está acostumado com palavras novas e abreviações de escrita. Sabemos que o cordel possui uma linguagem quase que padrão, porém eu tento adaptar os meus textos a esse novo universo de palavras e abreviações sem perder o foco. (Cordelista - Um cordel).

Comecei a escrever alguns textos já pensando na possibilidade deles se transformarem em vídeos. Também comecei a receber pedidos de cordéis personalizados, mais uma demanda que comecei a atender por conta da Internet. (Cordelista - Cordel animado).

Do mesmo modo que percebem as alterações nos modos de escrita, os cordelistas também entendem os deslocamentos resultantes do escrever para a Internet, com as tecnologias digitais. A literatura de cordel vive um momento de transgressão do suporte textual. Ao alcançar o ciberespaço passa a integrar-se a sons e imagens digitais, e é submetido aos diferentes mecanismos de interatividade e modalidades de escrita do universo hipertextual. Sobre as mudanças no texto poético, os cordelistas destacam:

o cordel lançado na Internet é diferente do escrito em folhetos, pois o da Internet é mais interativo, objetivo; não pode ser algo muito longo senão o público não tem interesse. Para divulgar o cordel na mídia é preciso ser algo que chame a atenção das pessoas, que as interesse. (Cordelista - Cordelando).

Acho que nenhum tipo de literatura precisa ser imutável. Uma característica interessante da Internet é essa cocriação, a maneira com que as pessoas absorvem a cultura e a ressignificam. Claro que é extremamente importante valorizar a autoria, a produção de todos os artistas, o clássico. Mas acho importante também abrir essa margem para que as pessoas possam criar algo sobre as bases do que já temos. (Cordelista 2 - Um repente por dia).

A principal diferença está na adaptação da linguagem. A essência continua, mas as mudanças são sempre necessárias. (Cordelista Um cordel).

Procuro nunca me distanciar dos elementos estruturais do gênero: métrica e rima, sobretudo.

(Cordelista - Cordel animado).

A interação mediada por computador possibilita ainda, uma descentralização do processo de escrita, viabilizando que ele aconteça de forma colaborativa. Conforme evidencia Demoly (2008: 119), "além da convergência de mídias, existe uma convergência de pessoas. Ferramentas interativas, disponibilizadas on-line, possibilitam atos de escrita coletivos, mesmo com participantes distantes geograficamente". Dos quatro cordelistas 
que entrevistamos, três afirmaram já ter feito parte de grupos virtuais de escrita colaborativa de literatura de cordel, e discorreram sobre o assunto:

\begin{abstract}
Participei de diversas coletâneas através da interação com poetas em grupos de Facebook e WhatsApp. Além de trabalhos conjuntos que viraram livros e folhetos, também interações que geraram vídeos para a Internet. É muito legal poder estar em contato com poetas cordelistas de todo o Brasil através das redes sociais; além de compartilhar meu trabalho com eles, posso também conhecer seu trabalho e aprender com as experiências exitosas deles com o cordel em seus territórios. (Cordelista - Cordelando).

Tenho um texto que comecei a produzir junto com uma amiga de São Paulo. Escrevemos juntos e em breve estará no site e na página. Tenho também alguns textos que viraram música, a nível de experiência é muito gratificante. (Cordelista - Um cordel).

Fiz uma peleja virtual via MSN, com uma parceira, cordelista. Também já fiz criações coletivas à distância, utilizando e-mail ou WhatsApp. Esse tipo de experiência é sempre muito interessante, e demonstra como a tecnologia encurta distâncias e aproxima pessoas. No caso específico do cordel pode ser usada e favor da sua preservação e difusão. (Cordelista - Cordel animado).
\end{abstract}

Compreendemos, portanto, que a experiência de escrever com as tecnologias digitais e de fazer com o outro, em regime de colaboração, potencializam novos processos cognitivos que transformam nosso ser/viver. É como afirma Lévy (1993: 17): "vivemos um destes raros momentos em que a partir de uma nova configuração técnica, quer dizer, de uma nova relação com o cosmos, um novo estilo de humanidade é inventado".

\title{
7. Considerações finais
}

Buscamos neste trabalho compreender como a mediação das tecnologias digitais influenciam o processo de escrita da literatura de cordel, potencializando novas experiências cognitivas. Nos aproximamos desse fenômeno a partir de uma imersão no ciberespaço, onde identificamos sites, blogs e páginas de redes socias com um grande número de publicações de obras em literatura de cordel. Após a seleção do nosso corpus, nos dedicamos a analisar essas publicações, com vistas a perceber possíveis alterações do gênero. A realização de entrevistas com os cordelistas que gerenciam e alimentam as páginas selecionadas também foi uma das estratégias metodológicas adotadas para tomarmos para nós suas percepções. Partimos do pressuposto de que um determinado dispositivo técnico, ao ser acoplado pelo homem, determina nele um processo interno criativo que só é possível devido à existência deste dispositivo. Logo, ao integrar as tecnologias digitais em seu processo de escrita, o homem transforma-se cognitivamente e desenvolve novas capacidades e habilidades 
que, consequentemente, implicam em mudanças no que está sendo produzido. Nas análises que fizemos da literatura de cordel produzida para Internet, constatamos essa pressuposição. Com temáticas cada vez mais abrangentes, temos no ciberespaço um cordel produzido para um público que está acostumado com informações em tempo real, um público que é, ao mesmo tempo, receptor e produtor de conteúdo, que entra em discussões sobre os mais variados assuntos, mesmo não sendo especialista em nenhum deles. Os próprios cordelistas visualizam essa diversidade de temas tratados pelos cordéis como um reflexo de estarem imersos no ciberespaço, da mesma forma que a utilização de diversas mídias na composição do cordel também se deve a essa nova dinâmica estabelecida no mundo virtual. Na literatura de cordel que circula na Internet, verificamos o cruzamento de textos, imagens e sons em uma única obra. O texto poético sai do imaginário do poeta e do ouvinte e ganha vida nas telas dos computadores, tablets e smartphones.

Conforme evidenciam os cordelistas, passou-se a produzir literatura de cordel especificamente para a Internet. Nesse processo, manter a estrutura formal do gênero continua sendo uma preocupação, tendo em vista o uso de diferentes métricas nos cordéis analisados, porém levando-se em consideração as especificidades do ambiente e de seus usuários. O cordel virtual tornou-se mais dinâmico, objetivo e interativo. A utilização das tecnologias digitais também oportunizou a escrita da literatura de cordel em redes de colaboração. Algumas experiências foram relatadas pelos cordelistas durante as entrevistas, as quais certamente serão observadas e discutidas em pesquisas posteriores (Guerra \& Quintela, 2016). Contudo, reafirmamos a necessidade de enxergamos os dispositivos técnicos para além de sua dimensão utilitarista. Ao tratarmos da escrita de literatura de cordel com tecnologias digitais, estabelecemos uma discussão acerca da subjetividade humana, de processos cognitivos que se atualizam e se transformam no operar com estes dispositivos.

\section{Referências Bibliográficas}

Amorim, M. A. (2007). No visgo do improviso ou a peleja virtual entre a cibercultura e tradição: comunicação e mídia digital nas poéticas de oralidade (tese de mestrado). São Paulo: Pontifícia Universidade Católica de São Paulo.

Batista, S. N. (1977). Antologia da literatura de cordel. Natal: Fundação José Augusto. Castells, M. (1999). A sociedade em rede. São Paulo: Paz e Terra. 
Chartier, R. (1998). A aventura do livro: do leitor ao navegador. São Paulo: UNESP.

Curran, M. J. (2014). Relembrando: a velha literatura de cordel e a voz dos poetas. Oxford: Trafford Publishing.

Demoly, K. R. A. (2008). Escrituras na convergência de mídias (tese de doutoramento). Porto Alegre: Universidade Federal do Rio Grande do Sul.

Dias, M. H. P. (2000). Hipertexto - o labirinto eletrônico: uma experiência hipertextual (tese de doutoramento). Campinas: Universidade Estadual de Campinas.

Domingues, Diana (1997). A humanização das tecnologias pelas artes. In D. Domingues (Org.). A arte no século XXI: A humanização das tecnologias (pp. 15-26). São Paulo: Fundação Editora da UNESP.

Duarte, E. C. C., \& Alcântara, S. S. (2011). Literatura e cibercultura: um olhar sobre os textos multimidiáticos na internet. Scripta Uniandrade, 2, pp. 190-207.

Fragoso, S., Recuero, R., \& Amaral, A. (2011). Métodos de pesquisa para internet. Porto Alegre: Sulina.

Gil, A. C. (2010). Como elaborar projetos de pesquisa. São Paulo: Editora Atlas.

Guattari, F. (1992). Caosmose: um novo paradigma estético. São Paulo: Editora 34.

Guerra, P., \& Quintela, P. (2016). Culturas de resistência e média alternativos. Os fanzines punk portugueses. Sociologia, Problemas e Práticas, N. ${ }^{\circ} 80$, pp. 69-94.

Hine, C. (2004). Etnografia virtual. Barcelona: UOC.

Lévy, P. (1993). As tecnologias da inteligência: o futuro da inteligência coletiva na era da informática. Rio de Janeiro: Editora 34.

Lévy, P. (1999). Cibercultura. São Paulo: Editora 34.

Lévy, P. (2007). A inteligência coletiva: por uma antropologia do ciberespaço. 5. ed. São Paulo: Loyola.

Machado, A. (2002). Arte e mídia: aproximações e distinções. Galáxia, 4, pp. 19-32. Acedido em https://revistas.pucsp.br/galaxia/article/view/1289/787

Mattos, C. L. G. (2011). A abordagem etnográfica na investigação científica. In C. L. G. Mattos \& P. A. Castro (Orgs.). Etnografia e educação: conceitos e usos (49-83). Campina Grande: EDUEPB.

Marques, M. O. (2006). Escrever é preciso: o princípio da pesquisa. 5. ed. Ijuí: Ed. Unijuí.

Resende, V. M. (2005). Literatura de cordel no contexto do novo capitalismo: o discurso sobre a infância nas ruas (tese de mestrado). Universidade de Brasília, Brasília.

Simondon, G. (1989). Du mode d'existence des objets techniques. Paris: Aubier Philosophie. 